\title{
EL DESAFÍO DE LA DOCENCIA: BIOGRAFÍA, ACTIVISMO Y REDES CURRICULARES EN LAS ESCUELAS ${ }^{1}$
}

\author{
THE CHALLENGE OF TEACHING: BIOGRAPHY, ACTIVISM AND \\ CURRICULAR NETWORKS AT SCHOLOS
}

\author{
Jimena de Garay Hernandez ${ }^{1}$ \\ Letícia Carolina Pereira do Nascimento ${ }^{2}$ \\ Marcio Caetano ${ }^{3}$
}

\section{RESUMEN}

Las biografías son fragmentos que nos presentan la vida de diversos puntos. Estas narran experiencias, tramas y construcciones de identidades. Aquí nos interesan los modos y las "verdades" sobre la sexualidad y como ellas sociabilizaron experiencias en las escuelas. Con tres docentes que actúan en escuelas de ciudades del interior de los estados de Rio de Janeiro e Rio Grande do Sul, presentamos los diferentes manejos con los cuales la sexualidad funcionó, cumpliendo una función de saber y poder. A través de las narrativas fue posible observar cómo los sujetos construyeron sus cadenas de significados y estructuraron sus performatividades. Estas operaron mediadas con la responsabilidad con el futuro de sus estudiantes, la imagen de buena/o profesional y la homofobia.

Palabras-clave: Discursos. Géneros. Sexualidad. Performatividades. Biografía.

\begin{abstract}
Biographies are fragments that present the life of various points. They narrate experiences, plots and constructions of identities. Here we are interested in the ways and "truths" about sexuality and how they socialized experiences in schools. With three teachers who work in schools in inland cities of the states of Rio de Janeiro and Rio Grande do Sul, we present the different ways in which sexuality worked, fulfilling a function of knowledge and power. Through the narratives it was possible to observe how the subjects constructed their chains of meanings and structured their performativities. These operated mediated with responsibility for the future of their students, the image of good professional and homophobia.
\end{abstract}

Keywords: Discourses. Genders. Sexuality. Performativities. Biography.

\footnotetext{
1 Atualmente é Professora Adjunta no Instituto de Psicologia da UERJ. Doutora em Psicologia Social pela Universidade Estadual do Rio de Janeiro. e-mail: jime_degaray@ hotmail.com

${ }^{2}$ Atualmente é Professora Assistente do curso de Pedagogia Universidade Federal do Piauí - UFPI. Doutoranda em Educação pela Universidade Federal do Piauí - UFPI/PPGEd. e - mail: lecarolpereira@gmail.com

3 Atualmente é Professor da Universidade Federal de Pelotas - UFPEL. Pós-doutor em Currículo e Narrativas Audiovisuais - UERJ. Doutorado em Educação pela Universidade Federal Fluminense (UFF). e - mail: marciocaetano@furg.br
} 


\section{BIOGRAFIAS: TRAYECTORIA Y DISCURSOS}

Las narrativas biográficas constituyen fragmentos discursivos sobre la vida de los sujetos que las relatan. Estas configuran discursivamente el reencuentro con las experiencias, pudiendo proveer las dimensiones necesarias para llevar a cabo los procesos de (auto) creación, de tramas y dramas de sociabilidades, de construcción de sus identidades y, sobre todo, de constituir un dispositivo de creación de sentido de las dinámicas de la vida en las que los sujetos están involucrados. Sus análisis ganan doble sentido, al permitirnos la reflexión tanto del propio proceso de su producción, como de interpretación narrativa de hechos vividos (CAETANO, 2016; PEREZ, 2003).

A partir de narrativas de docentes que transitan en la ilegibilidad sexual, que actúan en la red pública de enseñanza de ciudades de provincia brasileñas, presentaremos los discursos sobre sexualidad que produjeron efectos y que les gobernaron en las relaciones escolares y en su trayectoria de vida. Pensamos que los fragmentos narrativos aquí presentados serán capaces de ofrecernos algunos elementos de los discursos que gobernaron y regularon conductas y que, a su vez, produjeron efectos en la escuela y en esferas sociales más amplias de los sujetos. Se accedió a los y las profesoras en encuentros individuales que ocurrieron a lo largo de 2018. Los sujetos trabajan en la red pública de dos estados brasileños, Rio de Janeiro y Rio Grande do Sul, y poseen de 50 a 55 años. En este texto, los sujetos entrevistados serán llamados: Pedro, Paulo y Norma. Sus nombres fueron substituidos por otros nombres.

Pedro es profesor de educación artística, casado con una profesora de portugués desde hace 22 años, tiene una hija y un hijo. Impedido de ser bailarín clásico debido al racismo, nos afirmó en una narrativa que: "mi vida está marcada por la frustración, pero yo no estoy frustrado". Paulo da clases en dos escuelas de la red de enseñanza del estado. Sin estar orgánicamente en alguna organización LGBT, eligió la escuela como su espacio de activismo político y reivindica la identidad de 'profesor gay' como principio de su actuación. La profesora Norma es viuda. Al pasar por la experiencia de tener a su compañera viviendo con cáncer, Norma exigió licencia médica para cuidarla y, con esto, estableció una relación honesta y abierta con sus estudiantes. 
La biografía toma la narrativa del (sobre el) sujeto como centro de interés. Esta propone que, a través de relatos particulares, otras dimensiones pueden articularse más ampliamente hacia el entendimiento de los fenómenos sociales. Sin embargo, a pesar de que el texto narrado sobre sí se configure como un discurso coherente, linear y encadenado, en la narrativa biográfica, así como en las memorias, el pasado se edita, y justamente por eso se reconstruye discursivamente de manera no linear, con superposiciones de tiempo, reflexiones y espontaneidad. En este sentido, lo que regresa no es el pasado en sí, sino la (re) lectura de las experiencias almacenadas en la memoria y estimuladas bajo determinada circunstancia. En otras palabras, no es el pasado linear el que se reconstruye en la narrativa, sino aquello que fue interpretado y privilegiado en la experiencia que marcó el sujeto y que esta elige como importante para decir. Ese ejercicio parece llevar el sujeto que narra a encontrarse con fragmentos de sus memorias y a visitar un determinado pasado.

La opción por las trayectorias de vida emergió al considerarse la metodología adecuada para articular las dimensiones individuales con los fenómenos sociales de carácter más amplio. Consideramos importante destacar que pensamos la vida no solamente como un conjunto de acontecimientos, sino como experiencias vividas en un determinado tiempo y lugar y, sobre todo, bajo algunas circunstancias investigativas. La trayectoria de vida va más allá de la narrativa (auto) biográfica, ella no cabe en el discurso sobre si. Al enfocarse en el sujeto que es narrada, es posible dimensionarla en un contexto más amplio. Si entendemos que la constitución de identidad es relacional, las biografías del sujeto pueden ser conectadas/comparadas con las narraciones de otras historias de vida, en una dinámica que supone ir más allá de la sucesión cronológica individual o de la constitución de trayectoria de vida. Adoptar la trayectoria de vida aliada a la perspectiva cultural y pos-moderna fue, sobre todo, concebir al lenguaje como constituyente/integrante de la realidad. Fue comprender las narrativas como resultado de prácticas cotidianas, las cuales, a su vez, pueden ser consideradas históricas y denunciar las reglas que las gobernaron y las produjeron.

Los diálogos en esta trayectoria investigativa fueron tejiéndose con las innumerables redes de subjetividades que se cruzaron. No se trataba de un diálogo donde los cuerpos 
estaban separados radicalmente entre las identidades: investigador(a) e investigado(a). Lo que decimos es que estábamos atravesados por relaciones afectivas que se intensificaron con el conocimiento de nuestras marcas. Ese movimiento de aproximación nos permitió construir un diálogo mediado por nuestros intereses. Sin embargo, no eran apenas los nuestros los que se encontraban en juego, ellas también buscaron, a través de aquello que nosotros representábamos en el juego investigativo, la legitimidad y el reconocimiento sobre sus historias y de aquello que afirmaban como verdad de sus vidas.

La vida constituye el locus privilegiado de la experiencia, del saber y del conocimiento. El aprendizaje, ya sea involuntario o estructurado en currículos, es una acción socialmente construida, así, su constitución se inscribe en la biografía, porque esta se constituye en la experiencia. Y, en esos movimientos, la experiencia es entendida como aquello que nos atraviesa, nos toca, y a partir de la cual somos capaces de producir redes de significados. En este sentido, la experiencia no se constituye como mero acontecimiento de nuestras vidas. Ella produce afectos que elevan o disminuyen la potencia de un cuerpo, por eso ella es capaz de producir y dejar marcas. Las narrativas que profesores y profesoras traen emergen por medio de esas experiencias (BONDIA, 2002).

La vida cotidiana ofrece una multiplicidad de momentos, lugares, espacios, situaciones y relaciones en las cuales se originan actos formativos de aprendizajes. Con esto, pensamos haber explicitado que no vemos a la historia de vida bajo la lente de la racionalidad occidental moderna que ve al mundo como si todo dependiera de la acción consciente. Percibimos esta estrategia como eficaz justamente porque permite la comprensión de las múltiples especificidades que constituyen la complejidad del sujeto. Entendemos las narrativas (auto) biográficas como un trabajo de lectura de la experiencia que arquitecta, busca y reúne elementos para componer la trama de lo que es narrado. El tiempo de nuestras vidas es, por lo tanto, el tiempo que conseguimos narrar; es el tiempo articulado intensamente en una historia, es la historia de nosotras y nosotros mismos tal y como somos capaces de imaginarla, de interpretarla y de contárnosla y contársela a los y las demás. 
Diseñada en la configuración movediza de los tiempos actuales, la narrativa de vida está sometida a varias reconfiguraciones a lo largo de la trayectoria del sujeto. Nos constituimos como sujeto en construcción. Con esto, el viejo hábito humano de atribuir sentido al recorrido de vida, a través de las invenciones de sí, ya no se cristaliza en formas ordenadas y rígidas, como la humanidad un día juzgó experimentar. En cada acontecimiento, la historia es sujetada a una interpretación retrospectiva y nuevamente es retroalimentada y (re) significada. De ese modo, las expectativas, las aspiraciones y las voluntades proyectadas resultaron ser dependientes de cadenas interconectadas de recuerdos del pasado. Es como si todo el tiempo revisitáramos una lectura del pasado para justificar una configuración del yo, de los deseos, de la forma en que nos colocamos en el mundo en el tiempo presente.

Las dinámicas sociales permitidas en la actualidad nos colocan ante sujetos facetados, con biografías que no obedecen necesariamente a las expectativas y con innumerables rupturas identitarias. Las ideas sobre cuerpos originadas y determinadas en identidades, tales como las descritas por el sexo, por la maternidad o la paternidad, se fragilizaron en los tiempos actuales. Con la pluralidad de modelos y las crisis en el mundo del trabajo y del capital, las referencias de masculinidades y feminidades se re-significaron en los cuerpos, en los sexos y en los deseos.

Verificamos que el cuerpo se construye como proyecto pedagógico y la marcación que se ejecuta sobre este cotidianamente presupone inversión e intervención. Se ofrecen diversos subsidios que van a ayudar en este recorrido continuo de producción de si, resultando en el hecho de que el sujeto va a caminar rumbo al proceso de reconstrucción de su identidad social y sexual (CAETANO; SILVA JUNIOR; DE GARAY HERNÁNDEZ, 2014, p. 5, traducción libre).

Vimos con los autores y la autora que una de las consecuencias, aquella que consideramos la más problemática, de los movimientos de descentración del sujeto y la reconfiguración de las instituciones integradoras (clase social, escuela, familia etc.) en la posmodernidad es la separación entre el sujeto y los sistemas de protección social. Esta situación se traduce, en última instancia, en el hecho de que los sujetos asuman la responsabilidad de construir, por sí mismos, incluso relacionalmente, los caminos por el mundo y los significados de su existencia social. En esa lógica, el sujeto es el responsable por su fracaso y su éxito. Y justamente es esta la paradoja de esta sociedad, que, al considerar al 
sujeto como emprendedor de sí, 'liberándolo’ de sus obligaciones tradicionales de género, de grupo social ... no parece ofrecer otro final a su biografía sino la búsqueda ilimitada de proyectos que procuran una satisfacción aparentemente imposible de alcanzar: el sentimiento puede traducirse en angustia y vacío.

En la búsqueda de constituirse profesoras y profesores, nuestros personajes tomaron sus cuerpos como soportes de identidades que buscaron socioculturalmente los accesorios y comportamientos entendidos y reconocidos como propios de la profesión. Es en estos comportamientos que sus cuerpos buscan la confirmación, a través de la mirada del otro, de aquello que deseaban como verdad sobre lo femenino y lo masculino. Estos dispositivos/verdades modelan sus pensamientos y son familiares a sus formatos corporales, actuando como mecanismos de control y disciplina.

\section{EL ARTE DE HACERSE PROFESOR(A) CON LA ESCUELA HETERONORMATIVA}

Las biografías de los y las profesoras nos revelan el movimiento de justificación del presente con las acciones del pasado. Delory-Momember (2008) nos describe que eso es consecuencia de la búsqueda de unicidad de la narrativa biográfica. Según la autora, la "unicidad" se constituye sobre la acumulación de significaciones retrospectivas que reinterpretan implícitamente el curso de vida, inclusive sus lecturas y entendimientos anteriores. Estos aprendizajes son igualmente los lugares de experiencia, y por consiguiente, de construcción y justificación para las configuraciones de la identidad. En este caso, la configuración del sujeto, de sus deseos, de la forma en que se coloca en el mundo, es justificada por la experiencia. Sin embargo, lo que pudimos constatar en el proceso investigativo fue que la unidad biográfica se construye en la relación con las otras. Las experiencias, las significaciones y los caminos de la vida no actúan en una relación exclusiva consigo mismas; estas deben su contenido, forma y validez a las relaciones de estos sujetos y se encuentran en las redes de pertenencia. Por lo tanto, la unicidad biográfica estuvo limitada a un espacio-tiempo. 
Es justamente en las pertenencias en las que nos comprendemos como seres singulares. Los vínculos que aproximan a los sujetos unos a los otros son semejantes a los que establecen la reflexión de la propia vida; hacemos esa experiencia compartiendo los símbolos de las redes de pertenencia en las que estamos integrados/as; es a través de estas, con las biografías de otros, que nos gobernamos o que nos buscamos a nosotras y nosotros mismos. De esa manera, no cesamos de escribirnos, es decir, de componer los efectos de nuestra escritura biográfica en el cuerpo, al tiempo en que modelamos y autentificamos nuestros estilos, permitiendo reconocernos por las y los otros.

Observamos que, para los sujetos, la figura de sí se construye en una multiplicidad de configuraciones sociales, entre las cuales la escuela, la familia, la religión (instituciones reconocidas en la tradición medieval o en la modernidad como instituciones integradoras) no ocupan necesariamente posiciones prioritarias. Las instituciones sociales que los sujetos integran en la posmodernidad son más amplias y complejas que las observadas anteriormente, en las que tradicionalmente el tiempo-espacio de vida se dividía entre la familia, la escuela, la colonia, el trabajo, las actividades de ocio y los grupos de pertenencia, entre los cuales las instituciones religiosas se configura(ba)n como espacio privilegiado. Estos espacios ofrecían recorridos aparentemente estables y contornos ficticiamente coherentes, tales como el sexo. En la actualidad, en diferentes niveles, las instituciones descritas arriba tuvieron una implosión en sus significados y usos. Sería difícil conceptuarlas o incluso atribuir papeles y espacios de representación, a pesar de que, contradictoriamente, estas instituciones sean reivindicadas para legitimar las elecciones y verdades de los sujetos.

Transitar en ilegitimidad expone a los sujetos en situaciones cotidianas de enfrentamientos, Paulo nos cuenta que:

[...] Cuando entré a la docencia, ya comencé con un problema de homofobia [...] en el tercer año que estaba en la escuela, entró un muchacho, muchacho guapo, incluso, que venía de otra escuela. Él había golpeado a un profesor [...] decían que era problemático. [...] era medio complicado, no se adecuaba mucho a la escuela, lo que es normal. Generalmente, a un alumno complicado es bueno llamarlo a tu lado, ponerlo a ayudarte, él se siente más útil dentro de aquel esquema. El grupo fue a ver una película con una profesora y le pedí que lo dejara a él quedarse, porque quería hacer una máscara en él, ya que sería el ejemplo para el grupo. Como ella sabía que era problemático, lo dejó [...] Me quedé sólo con él en el salón, haciendo la máscara 
[...] La semana siguiente, le conté al grupo que íbamos a hacer una máscara. Fui al armario, agarré su máscara, "Miren, hicimos la máscara". Los alumnos preguntaron quién la había hecho, "Yo la hice en él", el grupo se inquietó mucho. Pregunté cuál era el problema. Un alumno dijo que yo me había ligado al muchacho y me dijo maricón [...] Él llegó a casa y le dijo al padre lo que había pasado, el padre fue a la escuela y dijo que no quería que su hijo tuviera clase con un profesor maricón. No quería que su hijo fuera gay en el futuro. Yo supe de eso después, cuando me contaron.

Las situaciones vividas por Paulo nos reafirman que el sexo regula y es normativo, como afirmó Michel Foucault (1983). Este no solo funciona e interpela los sujetos como norma, sino que también es capaz de producir los cuerpos que gobierna. En otras palabras, es una construcción que se perpetúa obligatoriamente a través del tiempo. No es una realidad simple o una condición estática del/en el cuerpo: el sexo es un proceso mediante el cual las normas reguladoras lo materializan y, a su vez, desarrolla la materialidad en virtud de la reiteración forzada de su norma (BUTLER, 2003).

Con la narrativa de Paulo, vemos que escribir sobre sexo, independientemente de la atribución que le damos, es producir discursos sobre el control y las prácticas pedagógicas sobre sexualidad. La regulación de la que hablamos parte del principio de que el entendimiento sobre el sexo habita todos los lugares y tiempos y se encuentra marcado en todos los cuerpos. El cuerpo es su outdoor. En ese sentido, el cuerpo es constituido como un proyecto pedagógico y las marcas que se ejecutan sobre él son cotidianas, de modo que lo localizan sobre determinados conjuntos de comportamientos sexuales. Eso supone inversión e intervención. Podemos verificar que, al contrario de lo que muchos defienden, las identidades asumidas y constituidas en las experiencias vividas están inscritas en las cosas y en los cuerpos a través de medidas implícitas en las rutinas cotidianas, en los rituales colectivos o privados de la escuela, familia, tecnologías mediáticas y tantas otras que nos seducen o nos obligan a participar.

Butler (2003) destaca que el proceso de construcción del género y de las sexualidades se hace ocultando sus orígenes. Así, a veces el sujeto se percibe a sí mismo, a su cuerpo, como naturalmente generificado, o como poseedor de una identidad de género naturalmente construida. La verdad, los procesos sociales producen y fijan identidades sexuales en los cuerpos. En una perspectiva genealógica, no es posible de hecho explicar los orígenes del 
género, por eso es interesante el análisis de las narrativas, pues estas permiten entender críticamente el modo en el que instituciones, prácticas y discursos producen el género. Más que ayudar a entender los orígenes de género, las narrativas permiten capturar los modos por los cuales el dispositivo de la sexualidad hace circular discursos que marcan los cuerpos, produciendo una determinada identidad sexual hegemónica en el ámbito de la heteronormatividad.

De acuerdo con Caetano (2016), en ese proceso de construcción de identidades, los propios sujetos se empeñan en la construciones de performatividades en sus cuerpos capazes da cuenta de sus géneros. Ese proceso se hace en confrontación con las normas regulatorias de género. Foucault (1980) propone que no siempre el poder reprime, los juegos de poder producen al sujeto, en una relación no apenas de coerción, sino también de resistencia. El proceso nunca termina, como señala Butler (2003), la materialización del género de la sexualidad es un proceso reiterativo. La materialización de las identidades sexuales no ocurre en un dado momento, esta es procesual e atraviesa toda la dimensión del tiempo que se vive, ella misma asume esa temporalidad, esa inestabilidad, la sexualidad necesita, por lo tanto, demarcarse constantemente.

La expresión de la identidad sexual es el resultado de inversiones heteronormativas articuladas, las cuales somos cotidianamente disciplinados y obligados a confirmar en acciones y accesorios. Las identidades de género y sexuales no son dadas, sino que resultan de una construcción que, a pesar de ser realizada por el sujeto, usa 'ladrillos' y 'cemento', es decir, los elementos culturalmente disponibles para la construcción del efecto.

\footnotetext{
La heteronormatividad no solo desea mantener la lógica dicotómica y complementaria entre hombres y mujeres, sino también la degradación social de los sujetos que buscan subvertirla. En este sentido, la homofobia y el machismo son respuestas de la heteronormatividad destinada a las sexualidades disidentes o a las mujeres. El sistema heteronormativo, para mantenerse en el orden de las cosas, necesita retroalimentarse de la lógica sexual binaria. De ahí viene la necesidad de controlar ideológicamente las tecnologías pedagógicas de la escuela y mais ampliamente da cultura. Nestes pressupostos, articulam-se as identidades e as prácticas curriculares (CAETANO, GOULART E SILVA, 2016, p. 43. traducción libre)
} 


\section{Revista \\ Debates Insubmissos}

Con los autores y la autora vemos que la construcción de los cuerpos-sexuados, naturalizados como diferentes, asimétricos y complementarios es un asunto más de la disputa de saberes que se instauró en la modernidad. Como el género es constituido y significado a través de tecnologías educativas asimétricas de ámbito cultural, social, político e histórico, es este el que significa al sexo. Por lo tanto, no existe in natura sexo sin género:

[Cuando el cuerpo viene a la luz del día], ya cargará un conjunto de expectativas sobre sus gustos, su comportamiento y su sexualidad, anticipando un efecto que se juzga. Cada acto del(a) bebé, el/la madre/padre lo interpretará como si fuera la "naturaleza hablando". Entonces, se puede afirmar que todos ya nacemos operados, que somos todos post-operados. Todos los cuerpos ya nacen "maculados" por la cultura. La interpelación que "revela" el sexo del cuerpo tiene efectos protéticos: hace los cuerpos-sexuados. Analizar los cuerpos como prótesis significa librarse de la dicotomía entre cuerpo-naturaleza versus cuerpo-cultura y afirmar que, en esta perspectiva, las/los mujeres/hombres biológicas/os y las/los mujeres/hombres transexuales se igualan. Esta es la primera cirugía a la que se nos somete. La cirugía para la construcción de los cuerpos sexuados. En este sentido, todos somos transexuales, pues nuestros deseos, sueños, papeles no son determinados por la naturaleza. Todos nuestros cuerpos son fabricados: cuerpo-hombre, cuerpo-mujer (BENTO, 2006, p. 02, traducción libre).

Hasta aquí hemos defendido que nuestros cuerpos son diariamente interpelados y las pedagogías que nos educan buscan milimétricamente diseñar nuestras configuraciones identitarias. Sin embargo, es necesario que sepamos que en las vivencias rutinarias de los sujetos, las identidades, son posteriores a la configuración cotidiana del cuerpo, esta es más ágil y rizomática, es menos capturada por la clasificación. Estas identidades necesitan, para existir, un 'teatro' discursivo que solicita su escritura lingüística a los recursos científicos, sociales, culturales e históricos.

La escritura lingüística de una sociedad normalizada es el efecto histórico de una tecnología de poder normatizadora centrada en la vida. Estas normas o códigos son aplicados de forma sutil, de modo que los poderes esencialmente normatizadores se vuelven aceptables. Se resalta que es a través de la ideología y de la hegemonía que se diseminan los discursos que determinan lo que es normal/anormal, cierto/equivocado, saludable/enfermizo. Caetano (2016) propone que en la medida en que el discurso dominante socialmente construye una "norma" sexual que debe seguirse, paradójicamente también traza aquello que no debe seguirse; dicho de otra forma: al definirse lo "normal", también se demarca lo "diferente". 
Ese proceso relacional, conforme demarca Hall (2003) es propio de las dinámicas identitarias en las que el Otro, por ser entendido como nuestro exterior constitutivo, establece nuestras singularidades. Las relaciones y confrontaciones entre lo "normal" y lo "diferente" no apenas producen polos antagónicos, ellas establecen una relación de interdependencia. Las identidades solo pueden producirse por medio de las diferencias, jamás fuera de estas. De cierto modo, por más perturbador que parezca, una identidad sólo pode establecerse en la relación con el Otro. No obstante, ese proceso, que debería tener una dimensión meramente relacional, se convierte dentro de la heteronormatividad en una jerarquización de las diferencias. La construcción de la identidad hegemónica está marcada por la exclusión del Otro.

En este juego dicotómico centrado en el gobierno político de la vida, Caetano (2016) observa que los grupos sociales que ocupan posiciones centrales "normales" tienen la posibilidad no solo de representarse a sí mismos, sino también de representar a los otros. El proceso de representación de los "anormales" nace a partir del punto de vista del dominante. El sujeto que pertenece a un grupo subordinado trae consigo toda la carga y todo el peso de la representación, reforzando así la forma en que se construyen las relaciones de poder y haciendo que percibamos cómo nacen las “políticas de identidad” (HALL, 2003).

Las identidades que se pluralizan en los espacios de poder se configuran como imágenes de determinados grupos y pueden ser traducidas en representaciones. De hecho, las identidades solamente existen en función de las representaciones (SILVA, 1994). Las imágenes creadas a partir del lenguaje o viceversa pueden funcionar como demarcadoras de la visibilidad social de las sexualidades. Aquello que está visible establece lo diferente.

Esta situación nos lleva a pensar que la diferencia demarcada en la narrativa del profesor Paulo no fue un simple atributo de la escuela. Esta es fundamentalmente social, política y culturalmente construida, y por eso debe interrogarse continuamente, de modo que se evite que esta asuma un carácter natural y esencializado. Esto es debido a que tratándose de seres humanos, es necesario tener claro que las primeras identidades observadas (sexo, color de piel, nacionalidad, entre otras) son apenas algunas de las innumerables identidades que los 
sujetos en las dinámicas escolares y más ampliamente en las relaciones sociales acumularán y/o descartarán a lo largo de su vida y su formación.

La categoría interseccionalidad, acuñada y usada ampliamente por el Feminismo Negro, parece ser útil para pensar la escuela también, en la medida en que permite articular cómo varios ejes de opresión componen las identidades culturales (AKOTIRENE, 2019). De ese modo, pensar el sujeto en una unidad es extremadamente incoherente con la multiplicidad de marcadores identitarios que atraviesan nuestras experiencias. Además de relacional y de depender del otro, a identidad también es fragmentada. El sujeto unificado es una ilusión, es efecto de relaciones de poder que objetivan la construcción de identidades homogéneas, estáticas y productivas para un cierto ordenamiento social.

Innumerables vertientes epistemológicas y por lo tanto políticas que problematizan las pedagogías culturales y que nos enseñan sobre la sexualidad, sobre todo las posestructuralistas, apuntan hacia la noción de que los sujetos, a lo largo de su desarrollo físico y psíquico, a través de las más diversas instituciones y acciones sociales, se constituyen como hombre y mujer en etapas que no son secuenciales, continuas o iguales y que de ningún modo serán concluidas o definitivas. Esto ocurre justamente porque los campos culturales e históricos en los que se forman los discursos sobre la sexualidad y/o incluso las ideas más amplias en torno a los sujetos, son implicados de conflictos y son capaces de producir múltiples sentidos que no siempre son convergentes con las nociones sexuales hegemónicas de determinado contexto.

Las nociones esencialistas, universales y a-históricas en torno al sujeto y a aquello que este proyecta son simplistas, porque no destacan la diversidad de etapas por las cuales las culturas construyen y marcan sus cuerpos y significan sus configuraciones identitarias. Si consideramos los géneros con otras marcas sociales (clase, raza, generación, religión, nacionalidad) tendremos una infinidad de arreglos y presentaciones.

Esta pluralidad de presentaciones fragiliza el discurso unívoco en torno a la id-entidad. La arcaica idea de que el $i d$ daría las bases enraizadas y coherentes de la entidad "Yo", parece estremecerse con la identidad e inaugurar otra posibilidad de pensarla. En esta otra coyuntura, 
esta se nos presenta por su múltiple posibilidad, o sea, esta se configura como identificación (vinculada a la fantasía de la identidad).

La variabilidad performativa de la identificación (en la que los deseos o las fantasías sobre una determinada identidad realizan performances, es decir, lecturas individuales sobre la identidad), presupone el ejercicio de libertad (condición central en la invención de las cosas, de las creatividades pedagógica y de las sexualidades). Ese es precisamente el motivo por el cual la identificación de Paulo y Pedro también nos desestabiliza, desestructura, incomoda y extasía a nosotros/as, ávidos/as investigadores/as.

Estos re-haceres biográficos están inscritos en configuraciones sociales postmodernas que nos reclutan a varios estilos de vida que se nos presentan a través de nuevas tecnologías (medios de comunicación, internet, biomedicina, cirugías plásticas, entre otras), permitiéndonos la ampliación de nuestras experiencias personales, profesionales y la percepción de nuestras corporalidades. Estos, a su vez, interpelan nuestra proyección de género e influyen la forma en la que nos percibimos, nos articulamos y nos narramos en nuestras redes de sociabilidades.

Con la invención de sí, los reconocidos marcadores de género ${ }^{4}$, por sí mismos, ya no son nominaciones que nos sirven para legitimar el sexo de nacimiento y estabilizarnos frente a la cadena de identidades que presentamos/soportamos en nuestros cuerpos. En esta sociedad, en la que se ofrecen innumerables posibilidades identitarias, los y las consumidoras son considerados los y las ciudadanas. Así, en esta, los y las ciudadanas se orientan en dirección a la productividad de su individualidad, que se agota en su proprio proyecto. En el campo de la ingeniería del cuerpo, son estas infinidades que se inscriben en las articulaciones entre género,

\footnotetext{
4 En algunos campos de la vida y de sus relaciones, los marcadores de género están tan confusos que no nos permiten afirmar que se refieren a mujeres u hombres, tales como los comportamientos, accesorios simbólicos y expresiones corporales. Sin embargo, en otros, estos aún están enraizados y fundamentan las desigualdades entre hombres y mujeres, como en el campo económico, en las esferas de representación política y en los números de violencia doméstica y pública. Este último dato es interesante para reflexionar las diferencias sexuales entre los espacios, si en el orden reconocido como privado son ellas las mayores víctimas y ellos los mayores agresores, en el espacio público son ellos las víctimas y permanecen como los mayores agresores. Esto pone en evidencia una educación para la violencia y la complejidad existente entre las categorías género y sexo.
} 


\section{Revista \\ Debates Insubmissos}

sexualidad y pedagogías, ampliando, más allá de los procesos familiares y escolares, los medios por los cuales los sujetos configuran sus cuerpos y sus identificaciones.

El antagonismo entre la heterodesignación ${ }^{5}$ y la praxis cotidiana de las sexualidades contra-hegemónicas resulta en la reinvención de sus imágenes. Podemos percibir en las narrativas de los y las profesoras que el lugar heteronormatizado los obliga al juego disimulado de la duplicidad. Los sujetos se encuentran en el "entre-lugar" (BHABHA, 2006): aquel que trae hacia sus prácticas, la sensibilidad y los saberes de sus identificaciones, pero exactamente por conocer los códigos predominantes, optan por mantenerse, a la mirada del otro, en las identidades legitimadas en este espacio. Esta situación explica la astucia y el cuidado para mirar, oír, sentir y tocar las innumerables situaciones en que se contemplan sus identificaciones sexuales y más ampliamente los discursos sobre las sexualidades.

Lo que se destaca en estas reflexiones es la idea de que las relaciones de formación y coerción no se operan privilegiando a un sujeto, sino que se construyen en una compleja ingeniería en la que cada sujeto, en determinado tiempo y espacio, se configura en un lugar en esta tarea de asegurar el control sobre e otro y sobre sí. Estas configuraciones instauraron un debate con diferentes posiciones en cuanto a la evaluación de sus consecuencias subjetivas y sociales. Las corporalidades de profesoras y profesores afirman sus condiciones en un juego de proyecciones altamente controladas, milimétricamente calculadas en los entendimientos de lo femenino y a la espera de la confirmación de su condición. Cuando no obedecemos este estatuto, estamos sujetos la experiencia que Norma describe, que su colega de escuela vivió, conforme podemos verificar en la siguiente narrativa:

Guilherme enfrentaba, era osado. Guilherme no tenía un patrón de profesor
de segundo año, de seguir normas. Era un profesor universitario. Guilherme
no tenía este cuidado que yo tenía de ser educada, de no ofender al otro. Si él
tenía que hablar, hablaba, incluso hasta el fondo. Lo que quería era provocar
en serio. ¿Quién es Guilherme? Guilherme anda com hombres y con mujeres.
Era un personajazo, ¿entiendes? Esto trae aún más conflicto en el ambiente
de la escuela. Si la escuela ya es prejuiciosa con el tipo que decide ser un
homosexual, imagina con el que visiblemente es bisexual. La cuenta es
mucho mayor. Guilherme era un showman. [...] A Gilherme se le exigía

\footnotetext{
${ }^{5}$ Marta Rodríguez (1994) la describe como la definición del otro por parte de quien tiene el poder de la palabra (p. 220).
} 


\section{Revista \\ Debates Insubmissos}

mucho más que a mí, él es hombre, sin embargo, Guilherme transitaba en los dos corredores y él también hacía show. Todo esto era muy agresivo en la escuela. Si un homosexual ya agrede, ¿imagina un bisexual? Por esto, cualquier problemita con él asumía una proporción exagerada. Después él tuvo una demanda administrativa y salió de la escuela.

Con estas experiencias, verificamos que para ser profesora o profesor y sustentar esta identidad profesional, el sujeto está obligado a calcular cada movimiento, cada vestimenta, cada deseo, cada discurso, cada posición... El sexo es tomado como efecto panóptico que tiene, su estructura de vigilancia en el propio sujeto. La eficacia del poder productivo de la vigilancia ocurre exactamente porque cuenta con las innumerables pedagogías que sutilmente van interpelando, produciendo y naturalizando en el sujeto los mecanismos de internalidad de la mirada del vigilante, adquiriendo, así, en sí mismo, las funciones iniciales de la visión de quien lo mira.

La concepción de "poder disciplinar" de Foucault (2002) nos apoya en la comprensión de los procesos de construcción de los cuerpos-sexuados y de la incorporación de una estilística corporal, ya que se produce a partir de un conjunto de estrategias discursivas y no discursivas fundamentadas en la vigilancia de conductas apropiadas al sexo y la profesión. Una constante ortopedia discursiva que corrige los cuerpos que se desvían de las normas. Entre las técnicas de control, el panoptismo es el ojo constante del poder, el objetivo de esta técnica consiste en poner a los sujetos bajo una constante vigilancia jerárquica, al punto de que este pase a reconocerse en una condición de control. A partir de ese momento, los sujetos automatizan en sí mismos el poder de la vigilancia. El panoptismo es esencial para el poder disciplinar, pues perpetra en el individuo la constante vigilancia de sí mismo y de los otros.

Así, los cuerpos que están en la escuela permanecen en una vigilancia colectiva todo el tiempo. A pesar de que la infancia y la adolescencia, que componen el alumnado de las escuelas, son blancos privilegiados ese control, los relatos de los y las profesoras ponen en evidencia que estos también son atravesados por las normas del género y la sexualidad. Toda la arquitectura escolar está pensada para que no haya desvíos, para que pueda producirse y fijarse en todos los cuerpos la constitución de sujetos de una sexualidad saludable, higienizada, normalizada dentro de los patrones heteronormativos. 


\section{Revista \\ Debates Insubmissos}

Con los y las profesoras verificamos que las sexualidades disidentes son nombradas y especuladas en las formas, en el juego de presentaciones y en las expectativas heteronormativas de género. Estas, al estar inscritas y significadas en el cuerpo, están al interior de las jerarquizaciones y clasificaciones sociales, así como en los movimientos curriculares y, más ampliamente, en las acciones y relaciones escolares, es decir, en el sentido más amplio de currículo. La experiencia descrita a continuación de Pedro nos ejemplifica la afirmación:

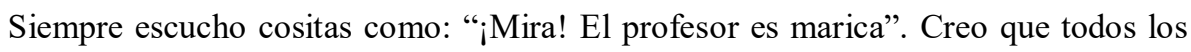
rótulos son posibles y esos rótulos existen entre los profesores. Ahora, existe una grande incógnita: ¿qué onda con Pedro? Un día el profesor de historia se volteó y me dijo: " $A$ Ah! Es porque eres artista. El artista cree que puede hacer de todo". Existe un profesor de ciencias de la noche cuyo gran deseo es saber qué onda conmigo. A fin de cuentas, al mismo tiempo en el que estoy casado y tengo dos hijos, tengo todas esas cosas con los alumnos y hago ballet. Existe todo eso en ese rótulo. Mi forma de vivir acaba dejando muy claro en todos lados: a los que les va a gustar Pedro y los que lo van a odiar. Los que van a respetar a Pedro como profesional que tiene su vida muy clara dentro de las expectativas de género masculinas y también aquellos que no soportan a Pedro que buscan, principalmente, al marica que está allí. Yo creo que esta es la forma en la que a las personas más les gusta desclasificar al tipo, diciéndole marica. Con los alumnos es la misma cosa. Existen los que conviven conmigo, esos son más cercanos y saben muy bien lo que pienso. Saben que creo que no deben existir rótulos y salimos. Para esos no existe eso de clasificar a Pedro como esto o como aquello. Pero también hay aquellos que me clasifican como maricón. Hay de todo [...] El Pedro homosexual surge si hay un momento político. Cuando hay ese momento político. En el día a día no tengo esa preocupación. La homosexualidad va a estar muy fuerte y necesita aparecer cuando necesite hacer un embate con la heterosexualidad. Cuando necesita, está en la lucha política. Yo no pienso en eso en este momento. En este momento [...] yo soy [...] ser humano que sabe que la vida es pasajera y que quiere vivir, que tiene una serie de posibilidades de vida y que sabe que tiene una serie de dificultades a enfrentar. Una vez te dije, nuestra vida está llena de "nos", pero no se compara con la de un negro. Tal vez, esté más llena de "nos". Nosotros tenemos que construir nuestra trayectoria a partir de esas negaciones y buscando caminos. Entonces, lo que yo busco para mí es eso. Es salir buscando caminos sin parar a pensar. Algunos van a recordarme a la mitad del camino [...] que soy maricón, que soy homosexual. Otros me van a recordar que soy negro. Otros van a recordarme algunas cosas. Pero yo quiero seguir mis posibilidades. Si el embate político vale la pena, me voy a acordar de lo que me dijeron y voy a ese embate político. Pero, fuera de eso, yo voy viviendo. No hay en 24 horas del día un momento en el que piense: ahora estoy con esa comunidad y mi relación con esa comunidad es" x", ahora estoy ahí y Pedro es "y". Si alguien vive conmigo 24 horas al día, va a conocer en cada lugar un sujeto que va a hablar de un Pedro diferente.

La trayectoria del profesor Pedro dialoga con el análisis del poder pensada por Foucault (2003), en lo respectivo a la vigilancia y castigo no apenas de la infracción 
cometida; no es solamente el desvío concreto que se castiga. El poder opera más allá del delito, se ejerce a partir de las virtualidades, de la noción de peligrosidad en la cual la sociedad juzga al individuo, no a partir de las infracciones, pero de las virtualidades de su comportamiento, en sus representaciones. En ese sentido, no importa si Pedro es o no homosexual, cualquier comportamiento que escape de la heteronormatividad lo va a poner en una condición de ser castigado. A partir de la noción de virtualidad, el individuo se vuelve potencialmente peligroso, amenaza las normas instituidas y por eso mismo merece ser vigilado y castigado.

Como ya sabemos, el discurso de género se significa como efecto de sofisticados equipamientos educativos y formativos mantenidos por instituciones como el derecho, la medicina, la familia, la escuela, la religión y especialmente el lenguaje, que producen cuerpos dicotómicos reconocidos como masculinos y otros identificados como femeninos. Esa dinámica busca ficticiamente ocultar otras posibilidades de identificaciones. Sin embargo, su ficción reside en el propio discurso que busca cohibir a proliferación de otros arreglos externos a la dicotomía sexo/género. Es justamente en la represión productiva, como nos llama la atención Foucault (1987), en la que se originan infinitamente (lo que imposibilita una coherencia entre práctica/discurso/identidad/práctica) los discursos sobre la sexualidad. En esos presupuestos se inscriben articulaciones entre las identidades y las prácticas pedagógicas, ampliando, más allá de los procesos familiares y/o escolares, los equipamientos educativos que engloban una compleja red, en cuyo interior los sujetos se transforman y aprenden a reconocerse como hombre o mujer... y/o LGBT...

En el cotidiano escolar de los sujetos entrevistados, la vivencia de la sexualidad se encuentra en una rede compleja de deseos, presentaciones y condiciones favorables a su práctica y proyección identitaria. Para que esos profesores y profesoras se mantuvieran em la escuela, fue necesario reunir la capacidad de control emocional y corporal, escamotear y reinventar deseos y, en algunos aspectos, mentir.

Con la narrativa del profesor Pedro verificamos que los discursos sociales, al intentar marcar idealmente un cuerpo entre los géneros, de modo que uno sea el complemento opuesto 
del otro, el propio discurso es, a nuestro parecer, la base que alimenta las especulaciones y las sexualidades disidentes. En otras palabras, ese ideal inalcanzable que la modernidad, sus tecnologías y alianzas puntuales con los principios judeo-cristianos crearon en torno a los sexos/géneros, permitió un cuerpo referencial, pero en el cotidiano, exactamente por su configuración económica, geográfica, cultural e histórica, los sexos/géneros asumieron innumerables contornos, buscaron escapar de la lógica dicotómica, pero todavía luchan contra la especulación, la nominación y el encuadramiento.

Lejos de constituir un estatuto sobre narrativas biográficas o movimientos curriculares, este trayecto fue un ejercicio de investigar con profesores y profesoras los movimientos heteronormativos y las tensiones cotidianas que produjeron acuerdos y subversiones. En esta lógica, nos parece que solamente el afecto al quehacer pedagógico y a las relaciones con los y las alumnas, en la dimensión subjetiva, personal y política que la palabra nos dá, podría hacer que los profesores Pedro y Paulo y la profesora Norma permanecieran en la escuela. La palabra afecto, más que significar un regreso al quehacer ilusoriamente despolitizado, significa encarar la escuela en sus movimientos curriculares, como espacio implicado de vida, de quehaceres, diferencias culturales y disputas político-pedagógicas.

Lo que nos dijeron los y las profesoras con sus palabras es que ellos y ellas poseen un compromiso con la escuela y con los y las estudiantes, y eso nos acerca a otra palabra: amor. Mientras las relaciones de amor y, por lo tanto, de afecto por la escuela y consecuentemente por el aprendizaje parezcan la sublimación idealizada de la sexualidad, debemos entender que amar tiene la capacidad de revertir su contenido y convertirse en odio por el aprendizaje, por la escuela y por todo aquello que pueda representar el y la profesora.

\section{CONSIDERACIONES FINALES}

La propuesta de este estudio fue reflexionar sobre la importancia de que la escuela esté atenta a las cuestiones de género y sexualidades que constantemente indagan las prácticas curriculares. Así, la escuela puede ofrecer posibilidades para la deconstrucción de la 
heterosexualidad como norma, creando posibilidades para que los y las alumnas construyan sus identidades sexuales de forma autónoma y que las diversas sexualidades puedan cohabitar en el contexto escolar. Con las experiencias de los y las profesoras, constatamos que en la sociedad postmoderna el cuerpo del sujeto se volvió el soporte de pluralidad, sus deseos son los artesanos de su identidad y la libertad el límite de su creatividad.

Los contornos y puntos que durante mucho tiempo referenciaron el sujeto universal o a una racionalidad iluminista, en la actualidad se escapan entre los dedos. Esta situación de fragmentación del sujeto universal no está distante de la escuela, sino que se refleja en sus prácticas, cuando verificamos agendas de varios colectivos de sujetos reivindicando espacios en los currículos y prioridades de la escuela. Podríamos afirmar que la escuela es parte importante de esa maquinaria socio-política de legitimidad social de los colectivos de sujetos. Con los sujetos polimorfos vemos la fragilidad o los años iniciales de la falencia de los saberes disciplinares en la escuela. Donde antes existían fundamentalmente saberes científicos codificados en libros didácticos, hoy emergen las políticas públicas afirmativas o de reparación social. Los horarios de clase, las prioridades de los y las profesoras y la gestión de la escuela son milimétricamente disputados por las necesidades de los colectivos de sujetos o intereses gubernamentales y económicos. En el espacio de la escuela, así como en los demás espacios sociales, actúan los más variados intereses, los cuales, con sus prioridades, buscan el bienestar y la legitimidad.

Durante este ejercicio narrativo podemos verificar la presencia de diversas feminidades y masculinidades presentes en los discursos de los y las profesoras. Esto reafirma la idea de que las categorías de género son construidas y que cada sujeto fabrica su cuerpo, realiza su desempeño y se presenta como un proyecto interminable, siempre buscando atender o responder a las expectativas creadas sobre lo que es su ser. Estas palabras pueden mostrar que en la práctica las identidades de género y sexuales pueden ser más amplias que las defendidas en los discursos o percibidas en las prácticas pedagógicas y en los actos curriculares. 


\section{REFERENCIAS}

AKOTIRENE, C. Interseccionalidade. São Paulo: Pólen, 2019. Coleção Sueli Carneiro.

BHABHA, H. O local da cultura. Belo Horizonte: Editora da UFMG, 2006.

BENTO, B. A reinvenção do corpo: sexualidade e gênero na experiência transexual. Rio de Janeiro: Garamond, 2006.

BONDIA, J. L. Notas sobre a experiência e o saber de experiência. Revista Brasileira de Educação. Jan-Abr de 2002, nº 19.

BUTLER, J. Problemas de gênero. Rio de Janeiro: Civilização Brasileira, 2003.

CAETANO, M. Performatividades reguladas: heteronormatividade, narrativas biográficas e educação. Curítiba: Appris, 2016.

CAETANO, M.; GOULART, T.; SILVA, M. Ensaio sobre a heteronormatividade: modos curriculares de aprendizagem das sexualidades e do gênero. Atos de Pesquisa em Educação. vol. 11, n. 2, ago./nov. 2016, p.634-655

CAETANO, M.; SILVA JUNIOR, P.; DE GARAY HERNANDEZ, J. Ninguém nasce homem, torna-se homem: as masculinidades no corpo e o corpo nas práticas curriculares das masculinidades. Revista Periódicus, 2a edição, nov/2014 - abril/2015. pp. 1-11.

FOUCAULT, M. História da sexualidade: a vontade de saber. Rio de Janeiro: Graal, 1980. Vol. 1.

FOUCAULT, M.. Microfísica do poder. Rio de Janeiro: Graal, 2002.

FOUCAULT, M.. A verdade e as formas jurídicas. Rio de Janeiro: Nau Editora, 2003.

HALL, S. A identidade cultural na pós-modernidade. Rio de Janeiro: DP\&A, 2003.

PÉREZ, Carmen. Professoras alfabetizadoras: histórias plurais, práticas singulares. Rio de Janeiro: DP\&A, 2003.

RODRÍGUEZ, M. El feminismo francés de La diferencia. In AMORÓS, C. Historia de la teoría feminista. Madrid: Instituto de Investigaciones Feministas de la Universidad Complutense de Madrid/Consejería de Presidencia, Dirección General de la Mujer, 1994.

SILVA, T. T. (Org.). O sujeito da educação: estudos Foucaultianos. Petrópolis: Vozes, 1994. SILVA, T. T. (Org.); HALL, S.; WOODWARD, K. Identidade e diferença: a perspectiva dos estudos culturais. Petrópolis, RJ: Vozes, 2000. 
Revista

Debates Insubmissos

Submetido em: 29/06/2020

Aprovado em: 16/07/2020 